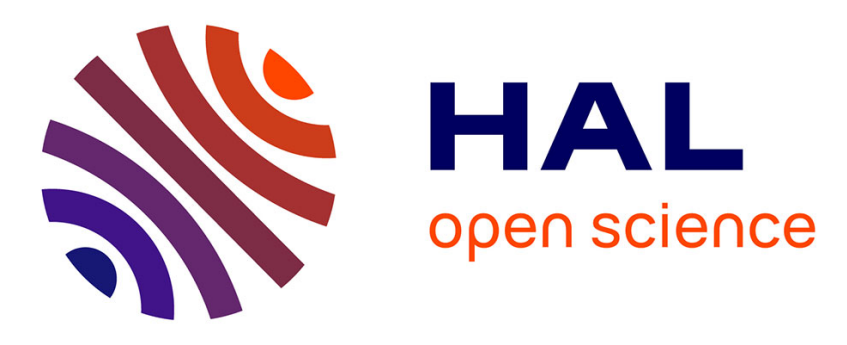

\title{
Experimental study of the hydrodynamic expansion following a nanosecond repetitively pulsed discharge in air
}

Da A. Xu, Deanna A. Lacoste, Diane L. Rusterholtz, Paul-Quentin Elias, Gabi D. Stancu, C. Laux

\section{To cite this version:}

Da A. Xu, Deanna A. Lacoste, Diane L. Rusterholtz, Paul-Quentin Elias, Gabi D. Stancu, et al.. Experimental study of the hydrodynamic expansion following a nanosecond repetitively pulsed discharge in air. Applied Physics Letters, 2011, 99 (121502), http://apl.aip.org/resource/1/applab/v99/i12/p121502_s1. 10.1063/1.3641413. hal-00651381

\section{HAL Id: hal-00651381 https://hal.science/hal-00651381}

Submitted on 13 Dec 2011

HAL is a multi-disciplinary open access archive for the deposit and dissemination of scientific research documents, whether they are published or not. The documents may come from teaching and research institutions in France or abroad, or from public or private research centers.
L'archive ouverte pluridisciplinaire HAL, est destinée au dépôt et à la diffusion de documents scientifiques de niveau recherche, publiés ou non, émanant des établissements d'enseignement et de recherche français ou étrangers, des laboratoires publics ou privés. 


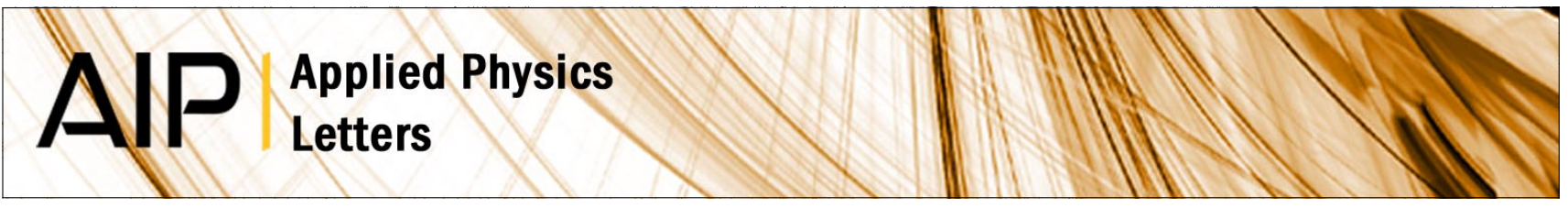

\section{Experimental study of the hydrodynamic expansion following a nanosecond repetitively pulsed discharge in air}

Da A. Xu, Deanna A. Lacoste, Diane L. Rusterholtz, Paul-Quentin Elias, Gabi D. Stancu et al.

Citation: Appl. Phys. Lett. 99, 121502 (2011); doi: 10.1063/1.3641413

View online: http://dx.doi.org/10.1063/1.3641413

View Table of Contents: http://apl.aip.org/resource/1/APPLAB/v99/i12

Published by the American Institute of Physics.

\section{Related Articles}

Regularized shock solutions in coating flows with small surface tension Phys. Fluids 23, 093103 (2011)

On the evolution of spherical gas interfaces accelerated by a planar shock wave Phys. Fluids 23, 084104 (2011)

Admissible shock waves and shock-induced phase transitions in a van der Waals fluid Phys. Fluids 23, 086101 (2011)

State resolved vibrational relaxation modeling for strongly nonequilibrium flows

Phys. Fluids 23, 057101 (2011)

Sound generation due to unsteady motion of a cylinder

Phys. Fluids 23, 046102 (2011)

\section{Additional information on Appl. Phys. Lett.}

Journal Homepage: http://apl.aip.org/

Journal Information: http://apl.aip.org/about/about_the_journal

Top downloads: http://apl.aip.org/features/most_downloaded

Information for Authors: http://apl.aip.org/authors

\section{ADVERTISEMENT}

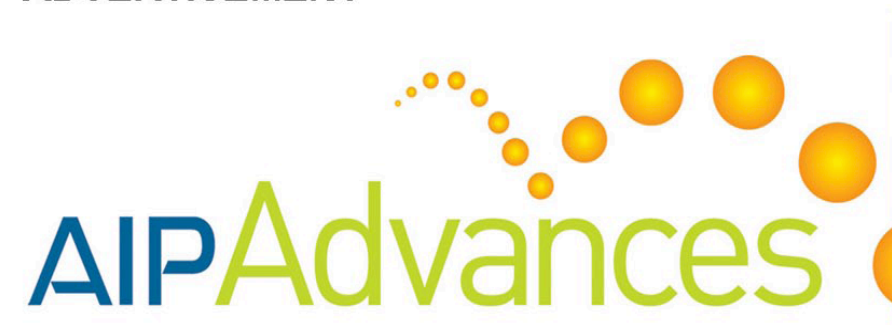

Submit Now

\section{Explore AIP's new \\ open-access journal}

Article-level metrics now available

Join the conversation!

Rate \& comment on articles 


\title{
Experimental study of the hydrodynamic expansion following a nanosecond repetitively pulsed discharge in air
}

\author{
Da A. Xu, ${ }^{1,2, a)}$ Deanna A. Lacoste, ${ }^{1,2}$ Diane L. Rusterholtz, ${ }^{1,2}$ Paul-Quentin Elias, ${ }^{3}$ \\ Gabi D. Stancu, ${ }^{1,2}$ and Christophe O. Laux ${ }^{1,2}$ \\ ${ }^{1}$ Laboratoire EM2C, CNRS/UPR 288, Grande Voie des Vignes, Chatenay-Malabry 92295 , France \\ ${ }^{2}$ Ecole Centrale Paris, Grande Voie des Vignes, Chatenay-Malabry 92295 , France \\ ${ }^{3}$ ONERA DMPH, Chemin de la Hunière, Palaiseau 91761, France
}

(Received 28 July 2011; accepted 29 August 2011; published online 21 September 2011)

\begin{abstract}
We report on an experimental study of the hydrodynamic expansion following a nanosecond repetitively pulsed (NRP) discharge in atmospheric pressure air preheated up to $1000 \mathrm{~K}$. Single-shot schlieren images starting from 50 ns after the discharge were recorded to show the shock-wave propagation and the expansion of the heated gas channel. The temporal evolution of the gas temperature behind the shock-front is estimated from the measured shock-wave velocity by using the Rankine-Hugoniot relationships. The results show that a gas temperature increase of up to $1100 \mathrm{~K}$ can be observed $50 \mathrm{~ns}$ after the nanosecond pulse. (C) 2011 American Institute of Physics. [doi:10.1063/1.3641413]
\end{abstract}

Nanosecond repetitively pulsed (NRP) discharges are being increasingly used in various applications, in particular in plasma-assisted combustion, ${ }^{1-4}$ nanomaterials synthesis, ${ }^{5}$ $\mathrm{x}$-ray generation, ${ }^{6}$ biomedicine and biochemistry, ${ }^{7,8}$ and aerodynamic flow control. ${ }^{9}$ The key advantage of NRP discharges is their high energy efficiency, and thus low power consumption, to produce highly reactive atmospheric pressure air plasmas. For instance, NRP sparks can dissociate a large fraction of oxygen molecules and heat the gas by about $1000 \mathrm{~K}$ within a few tens of nanoseconds following each pulse. ${ }^{10-13}$ This effect has been attributed to the so-called ultrafast mechanism initially proposed by Popov. ${ }^{14}$ The ultrafast mechanism corresponds to the following two-step process:

$$
\mathrm{N}_{2}(X)+e \rightarrow \mathrm{N}_{2}(A, B, C, \ldots)+e
$$

$$
\mathrm{N}_{2}(A, B, C, \ldots)+\mathrm{O}_{2} \rightarrow \mathrm{N}_{2}(X)+\mathrm{O}+\mathrm{O}+\text { heat release }
$$

In the first step, which takes place during the high voltage pulse, nitrogen molecules are excited by electron impact to electronic states such as $A^{3} \Sigma, B^{3} \Pi$, and $C^{3} \Pi$. Next, these excited electronic states of $\mathrm{N}_{2}$ undergo a quenching process by oxygen molecules, ${ }^{15}$ producing atomic oxygen radicals and heat release within a few tens of nanoseconds. This ultrafast production of $\mathrm{O}$ was experimentally verified. ${ }^{16}$ The ultrafast heating was observed, however, with the assumption that the rotational and translational modes of $\mathrm{N}_{2}$ are equilibrated at all times. ${ }^{12,13}$

Direct evidence to further confirm the ultrafast heating by NRP discharges may be obtained by imaging the shockwave propagation starting from a few nanoseconds after the end of the NRP discharge. Most authors ${ }^{17-21}$ investigated hydrodynamics of spark in air or fuel-air mixtures with longer duration $(>0.5 \mu \mathrm{s})$ and greater energy input $(>10 \mathrm{~mJ})$, in

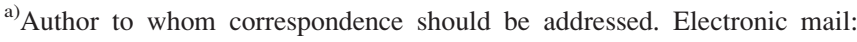
da.xu@ecp.fr.
}

a time region from several microseconds following the spark. Reinmann and $\mathrm{Akram}^{22}$ have extended the investigated time region to as early as $200 \mathrm{~ns}$ following the spark. To date, however, the hydrodynamics of the NRP sparks have not been examined. The small plasma dimensions, the short lifetime (tens to hundreds of nanoseconds), and the weakness of the shock-waves produced by the NRP discharges in heated air, make the investigation challenging.

In this letter, we present time-resolved, single-shot schlieren imaging of shock-wave and heated gas channel expansion induced by the NRP discharges. The NRP discharge setup ${ }^{12,13}$ is sketched in Fig. 1. The NRP discharges were generated between two refractory steel pin electrodes separated by an adjustable gap distance of $2-4 \mathrm{~mm}$. The pins had a diameter of $2 \mathrm{~mm}$ with sharpened tips and were placed in a vertical pin-pin configuration with the anode above the grounded cathode. The NRP discharges were created in preheated (300-1000 K) atmospheric pressure air. The roomtemperature or preheated air flow was introduced from the cathode side, flowing parallel to the pins at $0.5-2.6 \mathrm{~ms}^{-1}$. High voltage pulses of $10 \mathrm{~ns}$ duration, $1-10 \mathrm{kHz}$ pulse repetition frequencies (PRF), and 5-10 kV amplitude were produced by a solid-state pulse generator (FID). The voltage across the electrodes was measured with a LeCroy PPE20kV high-voltage probe. The current was measured with a

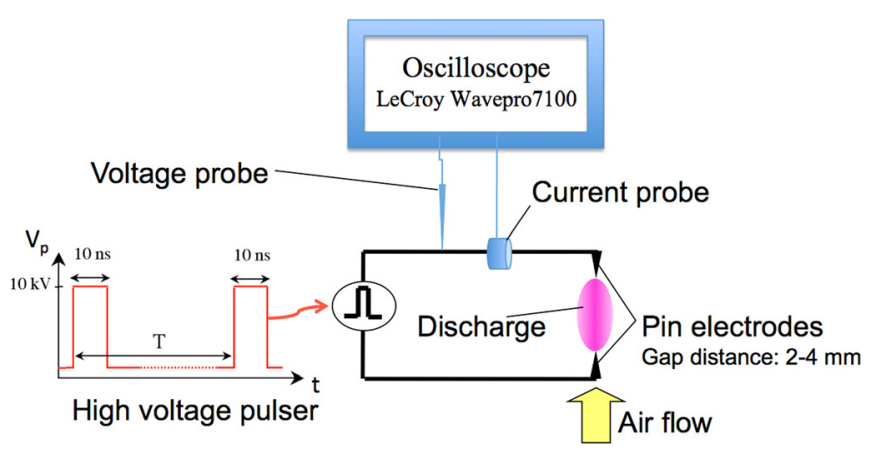

FIG. 1. (Color online) Schematic of the NRP discharge setup. 
Pearson coil (model 6585). Both signals were recorded simultaneously with a $1 \mathrm{GHz}$ oscilloscope. The spark energy was deduced from the voltage and current waveforms. ${ }^{13}$

The schlieren illumination was provided by a Nanolite flash lamp, which produces high-intensity, short duration arcs in air with a pulsing frequency of $1 \mathrm{~Hz}$ and a flash duration of about $20 \mathrm{~ns}$, sufficient to freeze the shock-wave for single-shot image recording. An intensified charge-coupled device (ICCD) camera (Princeton Instruments PI-MAX) with a $512 \times 512$ pixel resolution recorded the schlieren images with a well-defined exposure time window. The sensitivity of the schlieren system was ensured by a $2-\mathrm{m}$ focal length spherical mirror. The synchronization of the NRP discharge with the flash lamp and the ICCD camera was achieved with a Berkeley Nucleonics (BNC 575) multichannel pulse delay generator (200 ps RMS jitter).

Measurements were performed over a range of conditions. Here, three cases will be presented (see Table I). The first two cases were investigated in a $300 \mathrm{~K}$ air flow with a gap distance of $2 \mathrm{~mm}$, and Case 3 was in an air flow preheated to $1000 \mathrm{~K}$, with a $4 \mathrm{~mm}$ gap distance, similar to the discharges studied by Pai et al. ${ }^{12}$ and Stancu et al. ${ }^{16}$ The reduced electric field is determined to estimate fraction of energy transferred into heating. ${ }^{23}$ An example of successive schlieren images is shown in Fig. 2. The temporal evolutions of the shock-wave radius and of the heated gas channel radius in the middle plane of the gap are measured from the schlieren images and are shown in Fig. 3. The shock-wave velocity can then be deduced from the measured shock-wave radius evolution. It is found that initially the shock-wave accompanies the heated gas channel growth in a cylindrical shape and then propagates beyond the heated gas channel to form a spherical wave. The separation time can be varied from about 250 to $500 \mathrm{~ns}$ depending on the configuration case studied. As it propagates, the shock-wave degenerates into a sound wave. In all cases, the heated gas channels grow from a radius of about $0.4 \mathrm{~mm}$ and eventually dissipate in the surrounding air.

There are two major findings in the analysis of the results. First, the surrounding air temperature is inferred from the velocity of the pressure-wave degenerated from the discharge-induced shock-wave. The velocity of pressurewave lies so close to the speed of sound that the pressurewave can be considered as a sound wave. Sound-wave velocities in cases 1 and 2 are found to be $346 \pm 20 \mathrm{~m} / \mathrm{s}$ and $335 \pm 20 \mathrm{~m} / \mathrm{s}$, respectively, i.e., close to the value of the speed of sound in air at $300 \mathrm{~K}(347 \mathrm{~m} / \mathrm{s})$, indicating that in those cases, the NRP discharges do not appreciably heat the surrounding air. In contrast, in case 3 , the sound-wave velocity is found to be $773 \pm 50 \mathrm{~m} / \mathrm{s}$, corresponding to the sound speed at the temperature of $1500 \pm 200 \mathrm{~K}$, showing that the

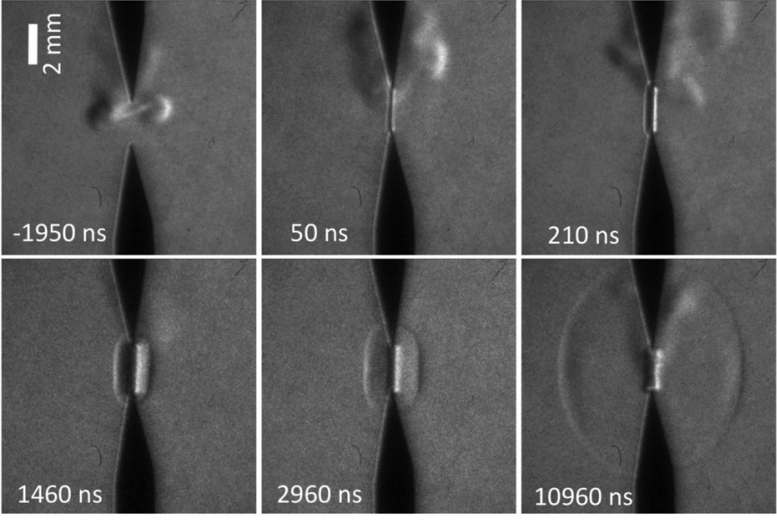

Case 1 (Gap distance $\left.=2 \mathrm{~mm}, P R F=1 \mathrm{kHz}, T_{\text {air flow }}=300 \mathrm{~K}\right)$

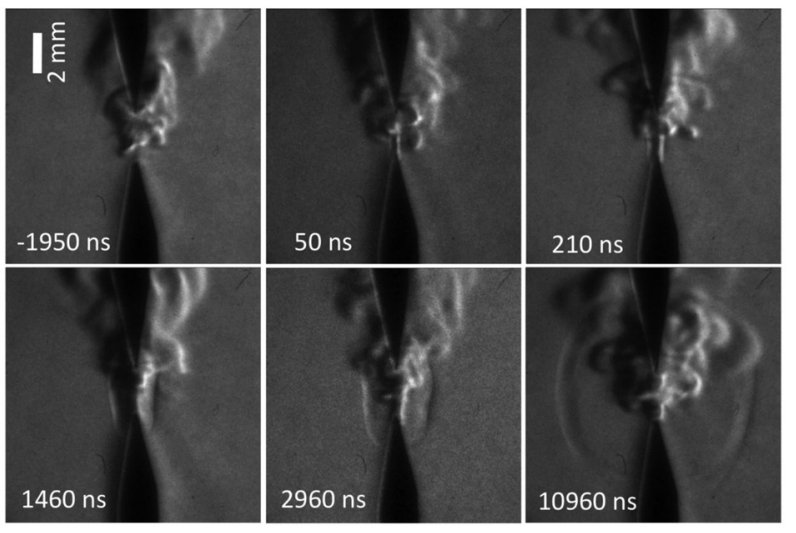

Case 2 (Gap distance $\left.=2 \mathrm{~mm}, P R F=10 \mathrm{kHz}, T_{\text {air flow }}=300 \mathrm{~K}\right)$

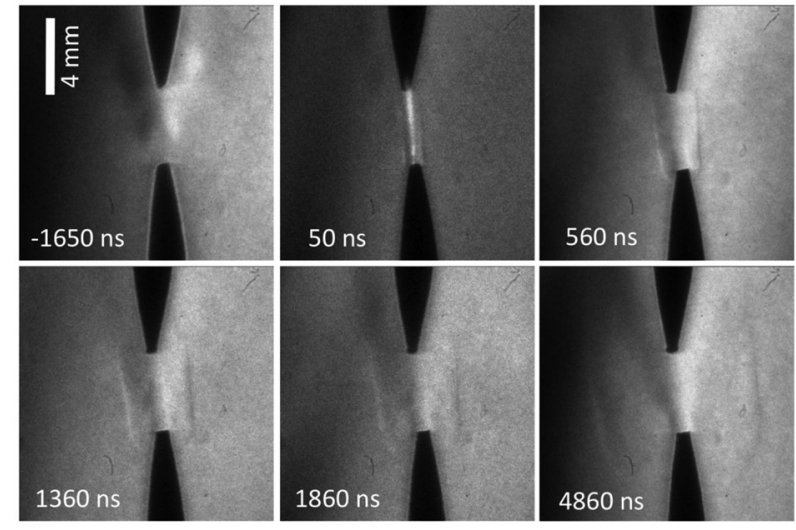

Case 3 (Gap distance $\left.=4 \mathrm{~mm}, P R F=10 \mathrm{kHz}, T_{\text {airflow }}=1000 \mathrm{~K}\right)$

FIG. 2. Examples of single-shot successive schlieren images. The exposure time is $20 \mathrm{~ns}$. Numbers below the images represent the elapsed time after discharge initiation. The minus sign indicates a time before the discharge. Note, in Case 2, that the gas heated by previous discharges has not been fully advected, but that the shock-wave expands at the same velocity as in Case 1 .

NRP discharges in this case heat the air in the vicinity of the discharge to an initial (i.e., preceding each pulse) temperature of about $1500 \mathrm{~K}$, a value consistent with the temperature

TABLE I. Summary of the three cases investigated.

\begin{tabular}{|c|c|c|c|c|c|c|c|c|}
\hline & Gap distance & Air flow temperature & PRF & Electric energy per pulse & $\mathrm{E} / \mathrm{N}$ & Energy transferred into heating ${ }^{\mathrm{a}}$ & $\mathrm{T}_{\text {initial }}$ & $\Delta \mathrm{T}_{\max }$ \\
\hline Case 1 & $2 \mathrm{~mm}$ & $300 \mathrm{~K}$ & $1 \mathrm{kHz}$ & $0.15 \mathrm{~mJ}$ & $150 \mathrm{Td}$ & $0.03 \mathrm{~mJ}$ & $\sim 300 \mathrm{~K}$ & $<200 \mathrm{~K}$ \\
\hline Case 2 & $2 \mathrm{~mm}$ & $300 \mathrm{~K}$ & $10 \mathrm{kHz}$ & $0.5 \mathrm{~mJ}$ & $126 \mathrm{Td}$ & $0.06 \mathrm{~mJ}$ & $\sim 300 \mathrm{~K}$ & $<200 \mathrm{~K}$ \\
\hline Case 3 & $4 \mathrm{~mm}$ & $1000 \mathrm{~K}$ & $10 \mathrm{kHz}$ & $1.6 \mathrm{~mJ}$ & $413 \mathrm{Td}$ & $0.57 \mathrm{~mJ}$ & $\sim 1500 \mathrm{~K}$ & $1100 \mathrm{~K}$ \\
\hline
\end{tabular}

${ }^{\mathrm{a}}$ Fraction of electric energy transferred into heating, based on the calculation results of Alexandrov et al. ${ }^{23}$ 


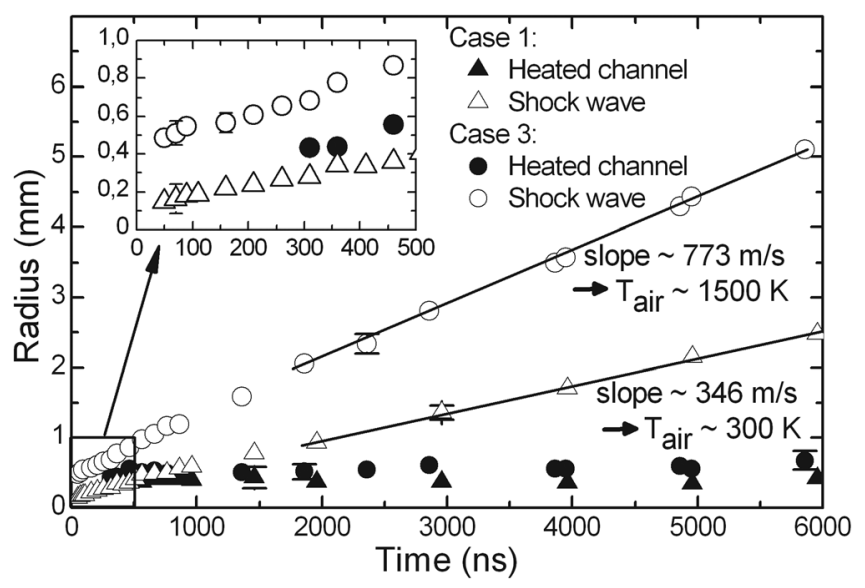

FIG. 3. Temporal growth of the shock-wave and heated-gas-channel radius measured in the middle plane of the gap for Cases 1 and 3. The data for Case 2 are not plotted because they are very similar to those of Case 1.

measurement based on $\mathrm{N}_{2}(C-B)$ spectra of the same type of discharges. ${ }^{12,13}$ The differences between the three cases can be explained by the different fraction of electric energy transferred into heating, as shown in Table I.

Second, the temperature and pressure behind the shock front can be obtained from the Rankine-Hugoniot relationships

$$
\begin{gathered}
\frac{p_{2}}{p_{1}}=\frac{2 \gamma_{1}}{\gamma_{1}+1}\left(\frac{u_{s}}{u_{1}}\right)^{2}-\left(\frac{\gamma_{1}-1}{\gamma_{1}+1}\right), \\
\frac{T_{2}}{T_{1}}=\left(\frac{p_{2}}{p_{1}}\right) \cdot \frac{\left(\gamma_{1}+1\right)+\left(\gamma_{1}-1\right)\left(p_{2} / p_{1}\right)}{\left(\gamma_{1}-1\right)+\left(\gamma_{1}+1\right)\left(p_{2} / p_{1}\right)},
\end{gathered}
$$

where $s$ denotes the shock-wave, 1 the condition ahead of the shock-wave (initial condition), 2 the condition behind the shock-wave, $u_{1}$ the acoustic velocity, and $\gamma_{1}$ the ratio of specific heats. From these relations, with the values of shockwave velocity deduced from Fig. 3 and assuming $T_{1}=300 \mathrm{~K}$ in cases 1 and $2, T_{1}=1500 \mathrm{~K}$ in Case 3, the temperatures evolution behind the shock-front are found (see Fig. 4).

Fig. 4 shows that in cases 1 and 2, the temperature behind the shock-wave remains close to $300 \mathrm{~K}$. In contrast, in case 3 , the maximum temperature reaches $2600 \mathrm{~K}$ in the first $100 \mathrm{~ns}$ and decreases rapidly afterwards. After the peak, the shock-wave experiences a deceleration and then again an acceleration between 260 and $500 \mathrm{~ns}$ (which is caused by the secondary discharge fired by the electrical circuit at about $250 \mathrm{~ns}$ ), and the temperature increases to a second peak of about $2300 \mathrm{~K}$.

The present results confirm the ultrafast heating mechanism of NRP discharges. This mechanism is consistent with the two-step mechanism involving electron-impact excitation of $\mathrm{N}_{2}$ followed by the dissociative quenching of the excited electronic states of $\mathrm{N}_{2}$ by $\mathrm{O}_{2}$. The ultrafast heating may have important applications in aerodynamic flow control, gas treatment, plasma-assisted combustion, or nanomaterial fabrication.

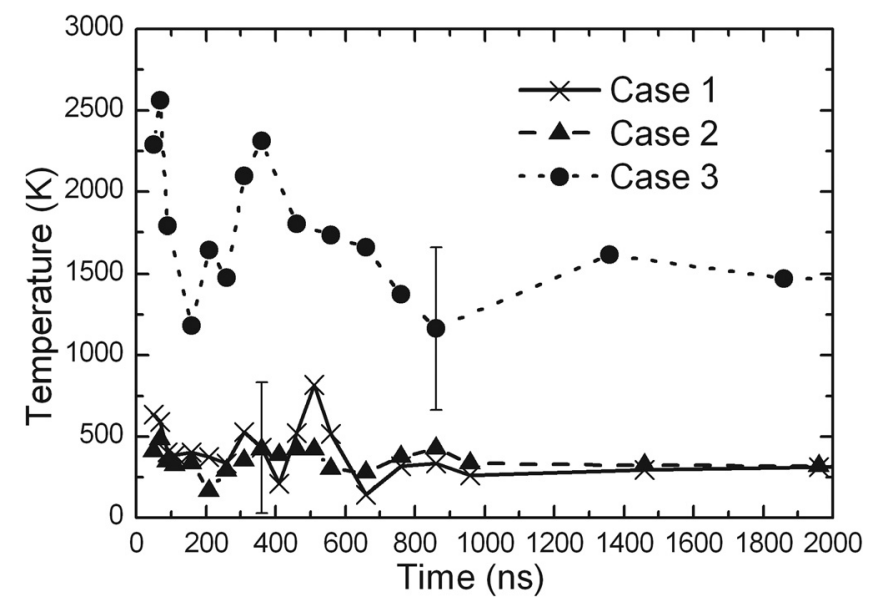

FIG. 4. Temperature behind the shock-wave versus time, based on RankineHugoniot relations.

This research has been supported by Agence Nationale de la Recherche PREPA project (Grant No. ANR - 09-BLAN-0043) and by a doctoral grant for one of the authors (D. $\mathrm{Xu}$ ) provided by the Erasmus Mundus Tandem Program. We thank Dr. T. Schuller and Dr. D. Durox for lending part of the schlieren equipment.

${ }^{1}$ G. Pilla, D. Galley, D. A. Lacoste, F. Lacas, D. Veynante, and C. O. Laux, IEEE Trans. Plasma Sci. 34, 2471 (2006).

${ }^{2}$ G. Pilla, Ph.D. thesis, Ecole Centrale Paris, 2008.

${ }^{3}$ S. V. Pancheshnyi, D. A. Lacoste, A. Bourdon, and C. O. Laux, IEEE Trans. Plasma Sci. 34, 2478 (2006).

${ }^{4}$ E. Mintusov, A. Serdyuchenko, I. Choi, W. R. Lempert, and I. V. Adamovich, Proc. Combust. Inst. 32, 3181 (2009).

${ }^{5}$ D. Z. Pai, J. Phys. D 44, 174024 (2011).

${ }^{6}$ V. F. Tarasenko, Appl. Phys. Lett. 88, 081501 (2006).

${ }^{7}$ S. Beebe and K. Schoenbach, J. Biomed. Biotechnol. 4, 297 (2005).

${ }^{8}$ P. Vernier, Y. Sun, L. Marcu, S. Salemi, C. Craft, and M. Gundersen, Biochem. Biophys. Res. Commun. 310, 286 (2003).

${ }^{9}$ D. F. Opaits, M. N. Shneider, and R. B. Miles, Appl. Phys. Lett. 94, 061503 (2009).

${ }^{10}$ P. Stritzke, I. Sander, and H. Raether, J. Phys. D 10, 2285 (1977).

${ }^{11}$ R. Maly, "Spark ignition: Its physics and effect on the internal combustion engine," in Fuel Economy in Road Vehicles Powered by Spark Ignition Engines, edited by J.-C. Hillard and G.S. Springer (Plenum Press, New York, 1984).

${ }^{12}$ D. Z. Pai, D. A. Lacoste, and C. O. Laux, Plasma Sources Sci. Technol. 19, 065015 (2010).

${ }^{13}$ D. Z. Pai, Ph.D. thesis, Ecole Centrale Paris, 2008.

${ }^{14}$ N. Popov, Plasma Phys. Rep. 27, 886 (2001).

${ }^{15}$ M. S. Bak, W. Kim, and M. A. Cappelli, Appl. Phys. Lett. 98, 011502 (2011).

${ }^{16}$ G. D. Stancu, F. Kaddouri, D. A. Lacoste, and C. O. Laux, J. Phys. D 43, 124002 (2010).

${ }^{17}$ R. Haley and P. Smy, J. Phys. D 22, 258 (1989).

${ }^{18}$ G. Ziegler, E. Wagner, and R. Maly, Symp. (Int.) Combust. 20, 1817 (1985).

${ }^{19}$ M. Kono, K. Niu, T. Tsukamoto, and Y. Ujiie, Symp. (Int.) Combust. 22, 1643 (1989).

${ }^{20}$ Y. Ko, R. Anderson, and V. Arpaci, Combust. Flame 83(1-2), 75 (1991).

${ }^{21}$ R. Freeman and J. Craggs, J. Phys. D 2(2), 421 (1969).

${ }^{22}$ R. Reinmann and M. Akram, J. Phys. D 30, 1125 (1997).

${ }^{23}$ N. Aleksandrov, S. Kindysheva, M. Nudnova, and A. Starikovskii, J. Phys. D 43, 255201 (2010). 